\begin{tabular}{|c|l|}
\hline Title & A Zn-porphyrin complex contributes to bright red color in Parma ham \\
\hline Author(s) & Wakamatsu, J.; Nishimura, T.; Hattori, A. \\
\hline Citation & $\begin{array}{l}\text { Meat Science, 67(1), 95-100 } \\
\text { https://doi.org/10.1016/.meatsci.2003.09.012 }\end{array}$ \\
\hline Issue Date & 2004 05 \\
\hline Doc URL & http://hdl.handle.net/2115/14763 \\
\hline Type & article (author version) \\
\hline File Information & MS67-1.pdf \\
\hline
\end{tabular}

Instructions for use 


\title{
A Zn-porphyrin complex contributes to bright red color in Parma ham
}

\author{
J. Wakamatsu*, T. Nishimura and A. Hattori \\ Meat Science Laboratory, Division of Bioresource \& Product Science \\ Graduate School of Agriculture, Hokkaido University \\ N-9, W-9, Kita-ku, Sapporo, Hokkaido 060-8589, JAPAN \\ * Corresponding Author \\ Jun-ichi Wakamatsu
}

Meat Science Laboratory, Division of Bioresource \& Product Science Graduate School of Agriculture, Hokkaido University N-9, W-9, Kita-ku, Sapporo, Hokkaido 060-8589, JAPAN (tel) +81-11-706-2547 (fax) +81-11-716-0879 (e-mail)jwaka@anim.agr.hokudai.ac.jp 


\section{Abstract}

2

3 The Italian traditional dry-cured ham (Parma ham) shows a stable bright red 4 color that is achieved without the use of nitrite and/or ni0trate. In this study we 5 examined the pigment spectroscopically, fluoroscopically and by using HPLC and 6 ESI-HR-MASS analysis. Porphyrin derivative other than acid hematin were 7 contained in the $\mathrm{HCl}$-containing acetone extract from Parma ham. A strong 8 fluorescence peak at $588 \mathrm{~nm}$ and a weak fluorescence peak at $641 \mathrm{~nm}$ were 9 observed. By HPLC analysis the acetone extract of Parma ham was observed at 10 the single peak, which eluted at the same time as $\mathrm{Zn}$ protoporphyrin IX and 11 emitted fluorescence. The results of ESI-HR-MS analysis showed both 12 agreement with the molecular weight of $\mathrm{Zn}$ protoporphyrin IX and the characteristic isotope pattern caused by $\mathrm{Zn}$ isotopes. These results suggest that

14 the bright red color in Parma ham is caused by Zn-protoporphyrin IX.

17 Keywords: Zn-protoporphyrin IX, Parma ham, heme, zinc, substitution 


\section{1 \\ 1. Introduction}

2

The color of meat and meat products are one of the important factors that determine the quality and is an important factor in the criteria by which consumers make selections. Myoglobin, which causes the red color of meat, is a heme protein with the iron complex of porphyrin, and the color of myoglobin depends on the kind of molecule coordinating to iron (Fox 1966; Ledward 1992; Sakata 2000). Deoxymyoglobin, without a ligand attached to iron, is the main constituent of meat that has just been cut, and deoxymyoglobin is later converted into oxymyoglobin, with oxygen. With the passage of time or with heating, oxymyoglobin is auto-oxidized and changes into metmyoglobin.

Myoglobin in meat products adding nitrate and/or nitrite is converted into stable red nitrosylmyoglobin coordinated to nitric oxide, and nitrosylmyoglobin changes into pink-reddish nitrosohemochromogen after the meat has been cooked. By the way the north Italian traditional dry-cured ham "Prosciutto di Parma (Parma ham)" is made from only the legs of fattened pigs and is salted with sea salt, dried, and matured over a period of one year. Despite the fact that nitrite and/or nitrate have not been added, the color is extremely stable bright red and is not changed by exposure of the ham to light or heat. Morita, Niu, Sakata \& Nagata (1996) reported that the red heme pigment was easily extracted with $75 \%$ acetone and that it is a new myoglobin derivative that is unknown in meat and meat products. Recently it was reported that this lipophylic stable red pigment in Parma ham increased with aging. (Parolari, Gabba, \& Saccani 2003) It has 
1 also been reported that bacteria obtained from meat products convert myoglobin

2 to the desirable red myoglobin derivatives (Faustman Johnson, Cassens \& Doyle,

3 1990; Arihara, Kushida, Kondo, Itoh, Luchansky \& Cassens, 1993; Arihara,

4 Cassens \& Luchansky, 1994; Morita, Sakata, Sonoki \& Nagata, 1994), but it is

5 not clear what the pigment is.

6 The objective of this study is to identify the stable red pigment in Parma ham

7 in order to obtain information for producing bright red meat products without 8 nitrite and/or nitrate.

9

10

11

12

13

14

\section{Materials and methods}

\subsection{Materials}

Zn protoporphyrin IX and hemin were purchased from Aldrich Chem. Co. (WI,

U.S.A.). Protoporphyrin IX $2 \mathrm{Na}$ salt was purchased from ICN Pharmaceuticals Inc. (CA, U.S.A.) An entire piece of deboned Parma ham was purchased from UNIBON Salumi S.C.ar.l. (Emilia Romagna, Italy). All other chemicals and solvents used in this study were of analytical grade.

\subsection{Extraction of porphyrins}

The thickest portion, which mainly consists of $M$. Semimembranosus, $M$. 
1 Semitendinosus, M. Biceps femoris, M. Rectus femoris, was transversely cut out

2 from an entire piece of deboned Parma ham and minced after removal of adipose 3 and connective tissue as much as possible. Minced sample (5 g) was 4 homogenized in 10 volumes of each of three kinds of ice-cooled solvents (distilled 5 water, $75 \%$ acetone (Okayama and Nagata 1978), and $75 \%$ acetone containing $6 \quad 0.7 \% \mathrm{HCl}$ (Okayama and Nagata 1979)) for $5 \mathrm{~min}$, and the homogenate was 7 filtered through a filter paper (No. 5C Toyo Roshi Co., Ltd., Tokyo, Japan). The 8 absorption and fluorescent spectrum of the filtrate were measured. 1959). Minced sample (5 g) was homogenized in 10 volumes of ice-cooled 11 distilled water, and the homogenate was centrifuged $\left(3,000 \mathrm{rpm}, 5 \mathrm{~min}, 4^{\circ} \mathrm{C}\right)$ and then filtered through a filter paper (No. 5C Toyo Roshi Co., Ltd., Tokyo, Japan). The $\mathrm{pH}$ of the filtrate was adjusted to 2 by using $0.1 \mathrm{~N} \mathrm{HCl}$, and then the equivalent of 2 -butanone was added. The 2-butanone layer was collected after strong mixture agitation. Demetalation of porphyrins was carried out by adding $6 \mathrm{~N} \mathrm{HCl}$. All of the operations were carried out under shading as much as possible.

\subsection{Isolation of the unknown red pigment from Parma ham}

homogenate was centrifuged $\left(3,000 \mathrm{rpm}, 5 \mathrm{~min}, 4^{\circ} \mathrm{C}\right)$ and then filtered through a 
1 ice-cooled acetone were added to the filtrate, and the mixture was placed in ice

2 for 15 minutes. The mixture was centrifuged at $3,000 \mathrm{rpm}$ for $5 \mathrm{~min}$ at $4{ }^{\circ} \mathrm{C}$.

3 An equal amount of distilled water was added to the supernatant, and the

4 mixture was applied to a disposable C18 column, Sep-Pak ${ }^{\circledR}$ Vac C18 Cartridge (12

5 cc/ 2g; Waters Co., MA U.S.A.) prewashed with $15 \mathrm{ml}$ of methanol and $15 \mathrm{ml}$ of

6 distilled water. The column was washed with $25 \mathrm{ml}$ distilled water and then the

7 red pigment was eluted with $10 \mathrm{ml}$ of $75 \%$ acetone.

$9 \quad$ 2.4. Absorption and fluorescent spectral analysis

10

8

The absorption spectra of the extracts were measured from 380 to $700 \mathrm{~nm}$ using a Model U-3210 spectrophotometer (Hitachi Ltd., Tokyo, Japan). The fluorescent spectra of the extracts were measured from 500 to $700 \mathrm{~nm}$ at $420 \mathrm{~nm}$ for excitation using a Model 650-60 fluorescence spectrophotometer (Hitachi Ltd., Tokyo, Japan).

\subsection{HPLC analysis}

HPLC was used to separate the red pigments in Parma ham by the method of Oshima, Yamada, Saito \& Hayakawa (1996). The HPLC system from Jasco Co. (Tokyo, Japan) was consisted of a Model 880-PU pump, a Model 870-UVi UV/VIS detector, a Model 820-FPi spectrofluorometer and a Model 802-SC system controller. The unknown red pigment isolated from Parma ham was dried up using a centrifugal evaporator (CVE-3100, Tokyo Rikakikai Co., Ltd., Tokyo, 
1 Japan) and solubilized in methanol:0.01 $\mathrm{M} \mathrm{Na}_{2} \mathrm{HPO}_{4}$ (76:24, v/v, pH 9). After

2 solubilization, the sample was filtered through $0.45 \mu \mathrm{m}$ filter (DISMIC-3, Toyo

3 Roshi Co., Ltd., Tokyo, Japan). A Shodex Asahipak ODP-50 4D column (4.6 ×

$4150 \mathrm{~mm}$, Showa Denko K.K., Tokyo, Japan) was used for separation of the red

5 pigment, and the separation was carried out by isocratic elution using the mobile

6 phase (methanol:0.01 $\mathrm{M} \mathrm{Na}_{2} \mathrm{HPO}_{4}=76: 24, \mathrm{v} / \mathrm{v}, \mathrm{pH}$ 9) at a flow rate of $0.5 \mathrm{ml} / \mathrm{min}$

7 at an ambient temperature. Twenty microliters of each sample was injected.

8 The eluent was monitored at $415 \mathrm{~nm}$ for excitation and at $590 \mathrm{~nm}$ for emission

9 wavelengths.

10

2.6. Electrospray ionization high resolution mass spectrometry (ESI-HR-MS) analysis diluted in a chloroform/methanol/acetone (1:1:8 v/v) solvent mixture was infused 17 into the ESI ion source at a flow rate of $1 \mu \mathrm{l} / \mathrm{min}$. The needle voltage and capillary voltage were $2681 \mathrm{~V}$ and $-1230 \mathrm{~V}$, respectively. The chamber 19 temperature was set to $105{ }^{\circ} \mathrm{C}$. A mixture of PEGs was used as an internal standard. 


\section{3 . Results and discussion}

2

The absorption spectra of the red pigments extracted from Parma ham by various solvents are shown in Fig. 1. The spectra of heme pigment extracted with water or $75 \%$ acetone were the same as those reported by Morita, Niu, Sakata \& Nagata (1996). On the other hand, when the red pigment was extracted with $75 \%$ acetone containing $0.7 \% \mathrm{HCl}$, the spectral pattern showed one absorption peak, at $409 \mathrm{~nm}$, in the Soret band and four peaks, at 509, 553, 600 and $637 \mathrm{~nm}$, in the visible range ( $\mathrm{Q}$ band). All heme pigments in meat products are extracted as acid hematin by $65-80 \%$ acetone containing $0.7-2 \% \mathrm{HCl}$ (Hornsey 1956; Okayama and Nagata 1979). Hornsey (1956) reported that the absorption peaks of acid hematin are observed only at 512 and $640 \mathrm{~nm}$ in the case of extraction with $80 \%$ of acetone containing $2 \% \mathrm{HCl}$. Our present result shows that a part of the red pigment in Parma ham is not transformed into acid hematin.

To determine the porphyrin structure of the red pigment in Parma ham, we attempted to remove the coordinated metal. The metal in the porphyrin metal complex is generally removed by treatment with a strong acid. Fig. 2 shows the absorption spectrum of the solution extracted with the acid-butanone. Although it was the same as that of the solution extracted with $75 \%$ acetone shown in Fig. 1 , the addition of $6 \mathrm{~N} \mathrm{HCl}$ resulted in a remarkable change in the absorption spectrum (Fig. 2). Although porphyrins generally have four absorption peaks in the $\mathrm{Q}$ band, metalloporphyrin shows on two peaks in the $\mathrm{Q}$ band due to the 
1 symmetry of the molecular structure. The spectral pattern after the addition of

$26 \mathrm{~N} \mathrm{HCl}$ was the same as that of protoporphyrin IX (data not shown). These

3 facts suggest that the red pigment in Parma ham is a metal complex of 4 protoporphyrin IX.

Although porphyrins generally show strong red fluorescence, the fluorescence

6 of metal complexes of porphyrin such as an iron complex (e.g., protoheme)

7 disappears. However, $\mathrm{Zn}, \mathrm{Mg}$ and $\mathrm{Cd}$ complexes emit fluorescence. Fig. 3

8 shows fluorescence spectra of red pigments extracted with distilled water or $75 \%$

9 acetone. A strong and a weak fluorescence peak at $588 \mathrm{~nm}$ and $641 \mathrm{~nm}$ were observed in both water- and acetone-extracts, respectively. Although data are

11 not shown, fluorescence was not detected in $75 \%$ acetone extract from raw pork.

It is suggested that the Parma ham red pigment is not iron complex like protoheme, because it was no fluorescence. $\mathrm{Mg}$ protoporphyrin IX is an intermediate in chlorophyll biosynthesis. Mg insertion into protoporphyrin IX is catalyzed by $\mathrm{Mg}$ chelatase (Walker and Willows 1997). The fluorescence emission peak of $\mathrm{Mg}$ protoporphyrin IX is $593-599 \mathrm{~nm}$ and that of $\mathrm{Zn}$ protoporphyrin IX is 583-589 $\mathrm{nm}$ (Castelfranco, Weinstein, Schwatcz, Pardo \& Wezelman, 1979; Fuesler, Wright \& Castelfranco, 1981; Masuda et al., 1999). Each peak wavelength is different and our result was similar with that of $\mathrm{Zn}$ protoporphyrin IX.

Therefore, we examined the possibility of the red pigment being $\mathrm{Zn}$ protoporphyrin IX using the HPLC method of Oshima, Yamada, Saito \& Hayakawa (1996). Hemin (Fe complex), Zn protoporphyrin IX (Zn complex) and 
1 protoporphyrin IX (metal free) were able to be distinctly separated, and

2 fluorescence of $\mathrm{Zn}$ protoporphyrin IX was only detected at $415 \mathrm{~nm}$ for excitation

3 (Fig. 4, traces 1 and 1'). In HPLC analysis of the unknown red pigment isolated

4 from Parma ham, a single peak with fluorescence was observed at the same

5 retention time as that of $\mathrm{Zn}$ protoporphyrin IX (Fig. 4, traces 2 and 2).

6 Additionally the reagent $\mathrm{Zn}$ protoporphyrin IX was diluted in $75 \%$ acetone, and

7 the spectral pattern was same as that of $75 \%$ acetone extract of Parma ham (data 8 not shown). ham, the highest molecular ion peak was detected at $m / z 624$ (Fig. 5). Six main 11 peaks were found when the peak region was expanded (Fig. 5 Insert). This peak pattern was agreed well with that of $\mathrm{Zn}$ protoporphyrin IX $\left(\mathrm{C}_{34} \mathrm{H}_{32} \mathrm{~N}_{4} \mathrm{O}_{4} \mathrm{Zn}\right)$ (Fig. 5, Insert), because $\mathrm{Zn}$ has five isotopes $(\mathrm{m} / \mathrm{z}=64,66,67,68$ and 70$)$ and the isotopic ratio is characteristic. Fe has four isotopes $(\mathrm{m} / \mathrm{z}=54,56,57$ and 58$)$ and its isotopic ratio entirely differ from that of $\mathrm{Zn}$. The exact mass of the principal molecular ion computed from the internal standard was 624.1711 and differed by

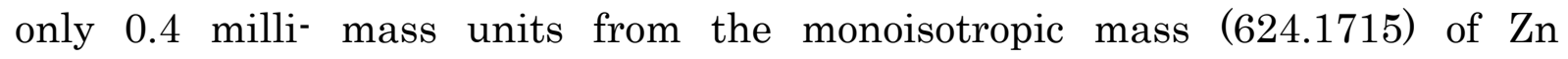
protoporphyrin IX. On the other hand, peaks originating in Fe protoporphyrin IX (MW 616.49), Mg protoporphyrin IX (MW 584.95) and Cd protoporphyrin IX (MW 673.05) were not observed. Our findings indicate that the red derivative in Parma ham is not only a Fe-porphyrin complex but also a Zn-porphyrin complex, namely, Zn protoporphyrin IX. Based on the results described above, it was 
1 conversion of an endogenous Fe-porphyrin complex, heme pigment, to a

$2 \quad$ Zn-porphyrin complex during the maturing process.

$3 \mathrm{Zn}$ is the most abundant metal after iron in a living body, but the amount of $4 \mathrm{Zn}$ in meat, i.e., in skeletal muscle, is greater than that of iron (Hazell 1982, 5 Kagawa 2001). Since Parma ham is manufactured using only pork and sea salt, 6 it is thought that something in these two raw materials or microorganism $7 \quad$ changes the Fe-porphyrin complex into a Zn-porphyrin complex. Ferrochelatase 8 (EC 4.99.1.1) catalyzes the insertion of $\mathrm{Fe}^{2+}$ into protoporphyrin IX in the final 9 step of heme synthesis (Porra and Jones, 1963a; Porra and Jones, 1963b). However, this enzyme is involved in the insertion of not only $\mathrm{Fe}^{2+}$ but various divalent metal ions, e.g., $\mathrm{Zn}^{2+}, \mathrm{Co}^{2+}, \mathrm{Ni}^{2+}$ or $\mathrm{Mn}^{2+}$ into porphyrins (Taketani and Tokunaga, 1981; Camadro and Labbe 1982; Bloomer, Reuter, Morton \& Wehner, 1983). The level of $\mathrm{Zn}$-chelating activity of ferrochelatase isolated from bovine liver was higher than that of Fe-chelating activity (Taketani and Tokunaga 1982). On the other hand, Zn is the second easiest metal after copper for insertion into porphyrins and is easily inserted into porphyrin without the requirement of a catalyst. Possible substitution systems are a non-enzymatic reaction, bacterial enzymatic reaction or endogenous enzymatic reaction. However, if it is an enzyme reaction, questions remain as to whether the endogenous enzyme activity is maintained during the long manufacturing process of Parma ham and whether bacterial enzymes permeate to the interior of ham. Future studies will focus on mechanism of $\mathrm{Fe}-\mathrm{Zn}$ substitution that occurs in Parma ham during the manufacturing. 


\section{4. Conclusions}

4

5 The absorption and fluorescence spectra of the red pigment extracted from

6 Parma ham are very similar to those of $\mathrm{Zn}$ protoporphyrin IX. The results of

7 HPLC analysis showed that the red pigment isolated from Parma ham with

8 acetone had the same retention time as that of $\mathrm{Zn}$ protoporphyrin IX. The

9 results of ESI-HR-MS analysis showed that the red pigment not only had a

10 molecular weight similar to that of Zn protoporphyrin IX but also showed the

11 characteristic pattern resulting from $\mathrm{Zn}$. It is suggested that the bright red

12 color in Parma ham is caused by $\mathrm{Zn}$ protoporphyrin IX in which the iron in the

13 heme of myoglobin has been replaced by $\mathrm{Zn}$.

14

15

16

17

18

\section{Acknowledgements}

We thank Mr. Kenji Watanabe and Dr. Eri Fukushi of the GC-MS and NMR Laboratory, Graduate School of Agriculture, Hokkaido University for performing the ESI-HR-MS analysis. 


\section{References}

Arihara, K., Kushida, H., Kondo, Y., Itoh, M., Luchansky, J. B., \& Cassens, R. G. (1993). Conversion of metmyoglobin to bright red myoglobin derivatives by Chromobacterium violaceum, Kurthia sp., and Lactobacillus fermentum JCM1173. Journal of Food Science, 58, 38-42.

Arihara, K., Cassens, R. G., \& Luchansky, J. B. (1994). Metmyoglobinreduktion durch Enterokokken. Fleischwirtschaft, 74, 1249-1250.

Bloomer, J. R., Reuter, R. J., Morton, K. O., \& Wehner, J. M. (1983). Enzymatic formation of zinc-protoporphyrin by rat liver and its potential effect on hepatic heme metabolism., Gastroenterology, 85, 663-668.

Camadro, J.-M. \& Labbe, P. (1982). Kinetic studies of ferrochelatase in yeast. Zinc or iron as competing substrates, Biochimica et Biophysica Acta, 707, 280-288.

Castelfranco, P. A., Weinstein, J. D., Schwatcz, S., Pardo, A. D., \& Wezelman, B. E. (1979). The Mg insertion step in chlorophyll biosynthesis. Archives of Biochemistry and Biophysics, 192, 592-598.

Faustman, C., Johnson, J. L., Cassens, R. G., \& Doyle, M. P. (1990). Color reversion in beef. Influence of psychrotrophic bacteria. Fleischwirtschaft, 70, 676-679.

Fox, J. B. Jr. (1966). The Chemistry of Meat Pigments. Journal of Agricultural and Food Chemistry, 14, 207-210.

Hazell, T. (1982). Iron and zinc compounds in the muscle meats of beef, lamb, 
pork and chicken. Journal of the Science of Food and Agriculture, 33, 1049-1056.

Hornsey, H. C. (1956). The colour of cooked cured pork. I. Estimation of the nitric oxide-heam pigments. Journal of the Science of Food and Agriculture, 7 , $534-540$.

Kagawa, Y. (Ed.) (2001). Standard table of food composition in Japan 2001. Tokyo: Kagawa Nutrition University Publishing Division.

Ledward, D. A. (1992). Colour of Raw and Cooked Meat. Special Publication. Royal Society of Chemistry, 106, 128-144.

Morita, H., Sakata, R., Sonoki, S., \& Nagata, Y. (1994). Metmyoglobin conversion to red myoglobin derivatives and citrate utilization by bacteria obtained from meat products and pickles for curing. Animal Science and Technology, 65, 1026-1033.

Morita, H., Niu, J., Sakata, R., \& Nagata, Y. (1996). Red pigment of Parma ham and bacterial influence on its formation. Journal of Food Science, 61, 1021-1023.

Okayama, T., \& Nagata, Y. (1978). (Japanese) A Modification of the method for measuring the color formation ability of meat products. Japanese Journal of Zootechnical Science, 49, 866-871.

Okayama, T, \& Nagata, Y. (1979). (Japanese) A method for the determination of total heme pigments in meat products. Japanese Journal of Zootechnical Science, 50, 15-21.

Oshima, H., Yamada, J., Saito, I., \& Hayakawa, J.. (1996). (Japanese) Heme, zinc 
protoporphyrin (IX) and heavy metals in edible tissues of livestock and poultry. Porphyrins, 5, 301-306.

Parolari, G., Gabba L., \& Saccani G. (2003) Extraction properties and absorption spectra of dry cured hams made with and without nitrate, Meat Science, 64, 483-490.

Porra, R. J., \& Jones, O. T. G. (1963a). Studies on ferrochelatase. 1. Assay and properties of ferrochelatase from a pig-liver mitochondrial extract, Biochemical Journal, 87, 186-192.

Porra, R. J., \& Jones, O. T. G. (1963b). Studies on ferrochelatase. 2. An investigation of the role of ferrochelatase in the biosynthesis of various haem prosthetic groups, Biochemical Journal, 87, 181-185.

Sakata, R. (2000). Studies on physicochemical characteristics of red pigments in meat products. Animal Science Journal, 71, 1-16.

Taketani, S., \&Tokunaga, R. (1981). Rat liver ferrochelatase. Purification, properties, and stimulation by fatty acids, The Journal of Biological Chemistry, 256, 12748-12753.

Taketani, S., \& Tokunaga, R. (1982). Purification and substrate specificity of bovine liver-ferrochelatase. European Journal of Biochemistry, 127, 443-447.

Teale, F. W. J. (1959). Cleavage of the haem-protein link by acid methylethylketone. Biochimica et Biophysica Acta, 35, 543.

Walker, C. J., \& Willows, R. D. (1997). Mechanism and regulation of Mg-chelatase. Biochemical Journal, 327, 321-333. 
1 Figures and tables

2

Fig. 1 Absorption spectra of heme pigments extracted from Parma ham with distilled water (a), 75\% acetone (b) and 75\% acetone containing $0.7 \% \mathrm{HCl}$ (c). The maximum absorption wavelengths are shown for the extracts.

Fig. 2 Absorption spectra of heme pigments extracted by the acid-butanone method (a) and then added one drop of conc. $\mathrm{HCl}(\mathrm{b})$. The maximum absorption wavelengths are shown for the extracts.

Fig. 3. Fluorescent spectra of heme pigments extracted from Parma ham with distilled water (a) and $75 \%$ acetone (b). The maximum absorption wavelengths are shown for the extracts.

Fig. 4. HPCL elution profile of the red pigment from Parma ham.

Traces 1 and 1', Standard solutions. Traces 2 and 2', Parma ham extract. Peaks are as follows; $H$ : hemin, $Z$ : zinc protoporphyrin IX, $P$. protoporphyrin IX.

Fig. 5. ESI-HR mass spectra of the red pigment from Parma ham and the magnification (insert). 


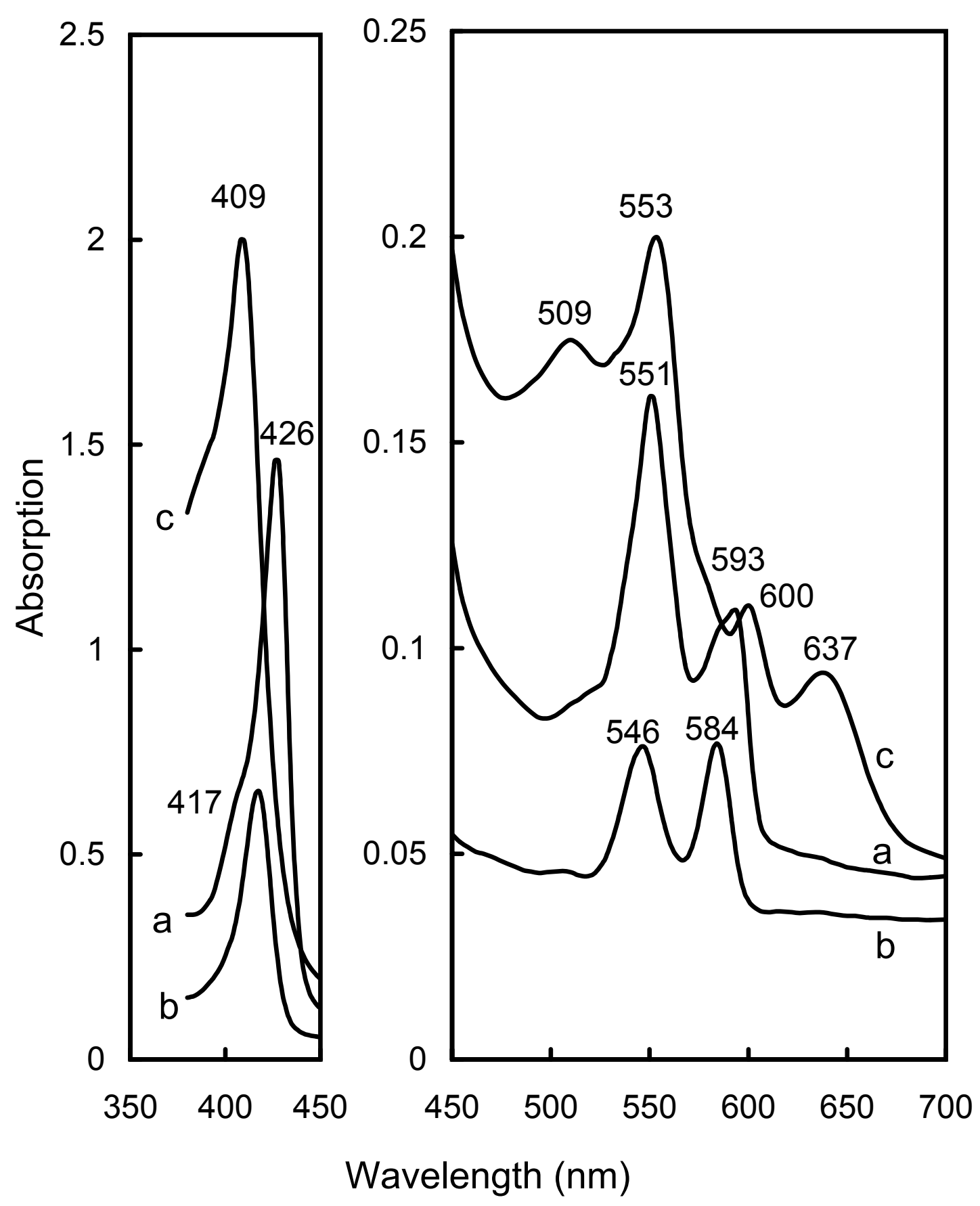

Fig. 1 Absorption spectra of heme pigments extracted from Parma ham with distilled water (a), $75 \%$ acetone (b) and $75 \%$ acetone containing $0.7 \% \mathrm{HCl}$ (c). The maximum absorption wavelengths are shown for the extracts. 


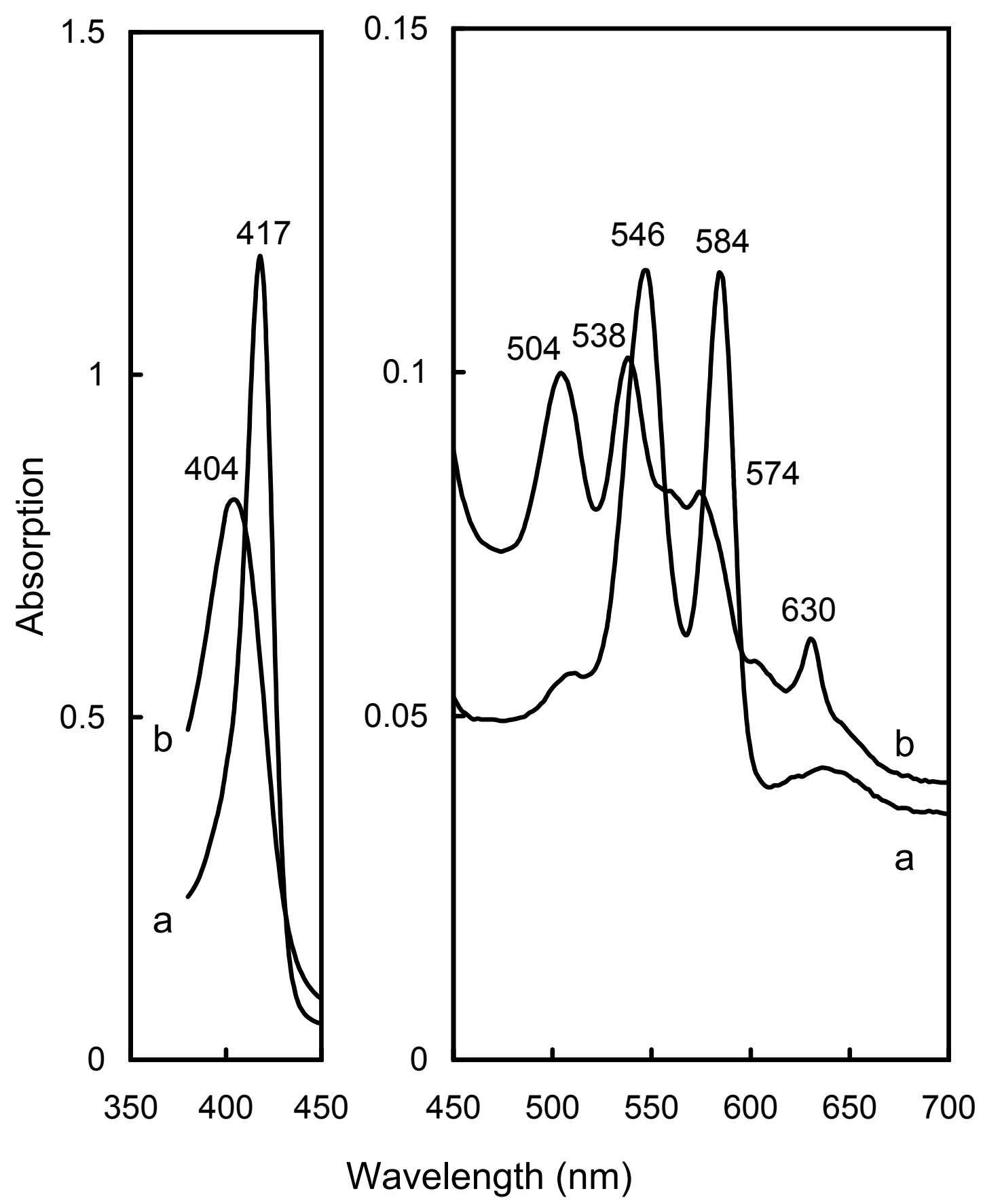

Fig. 2 Absorption spectra of heme pigments extracted by the acid-butanone method (a) and then with one drop of conc. $\mathrm{HCl}$ added (b). The maximum absorption wavelengths are shown for the extracts. 


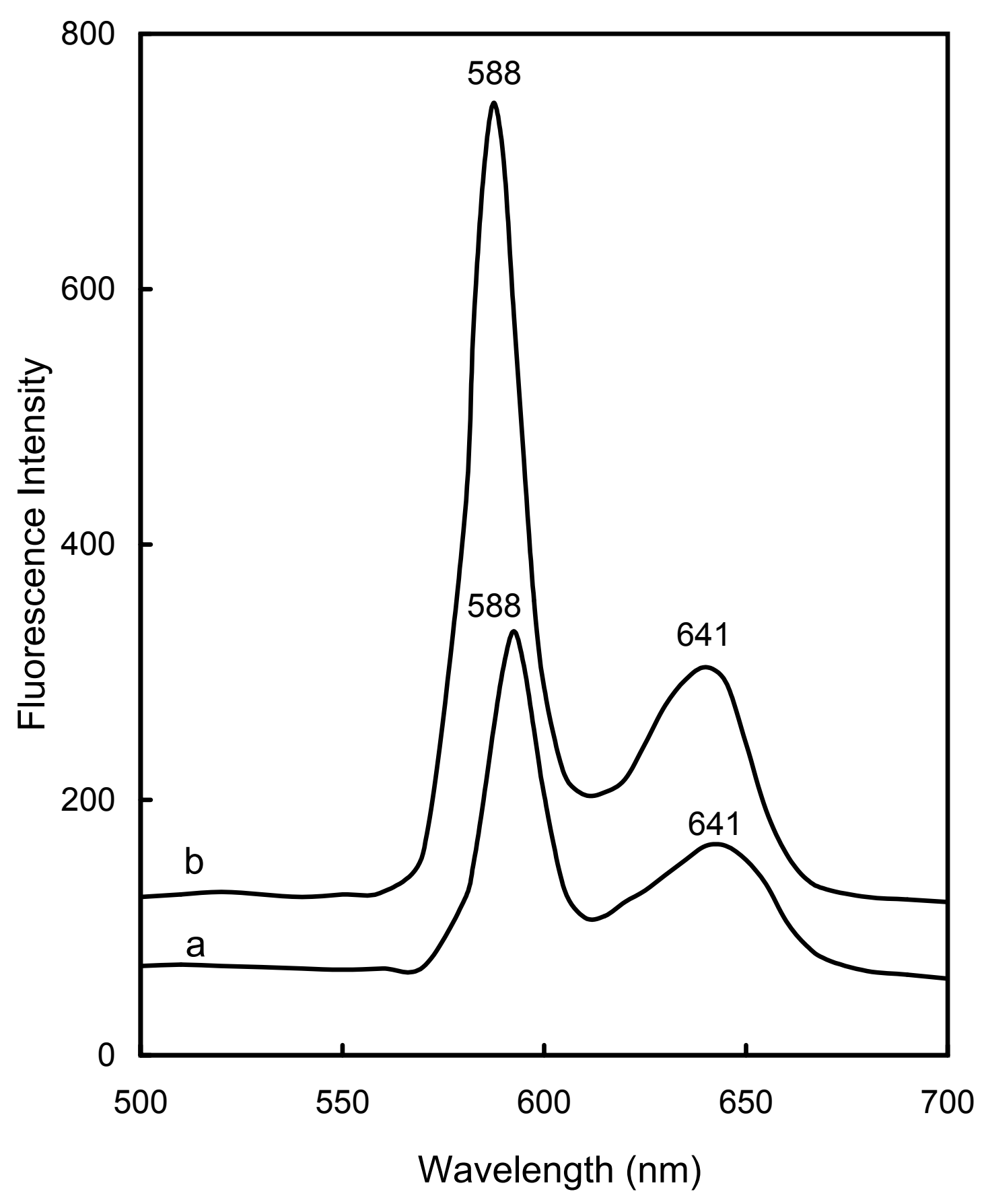

Fig. 3 Fluorescent spectra of heme pigments extracted from Parma ham with distilled water (a) and $75 \%$ acetone (b). The maximum absorption wavelengths are shown for the extracts. 

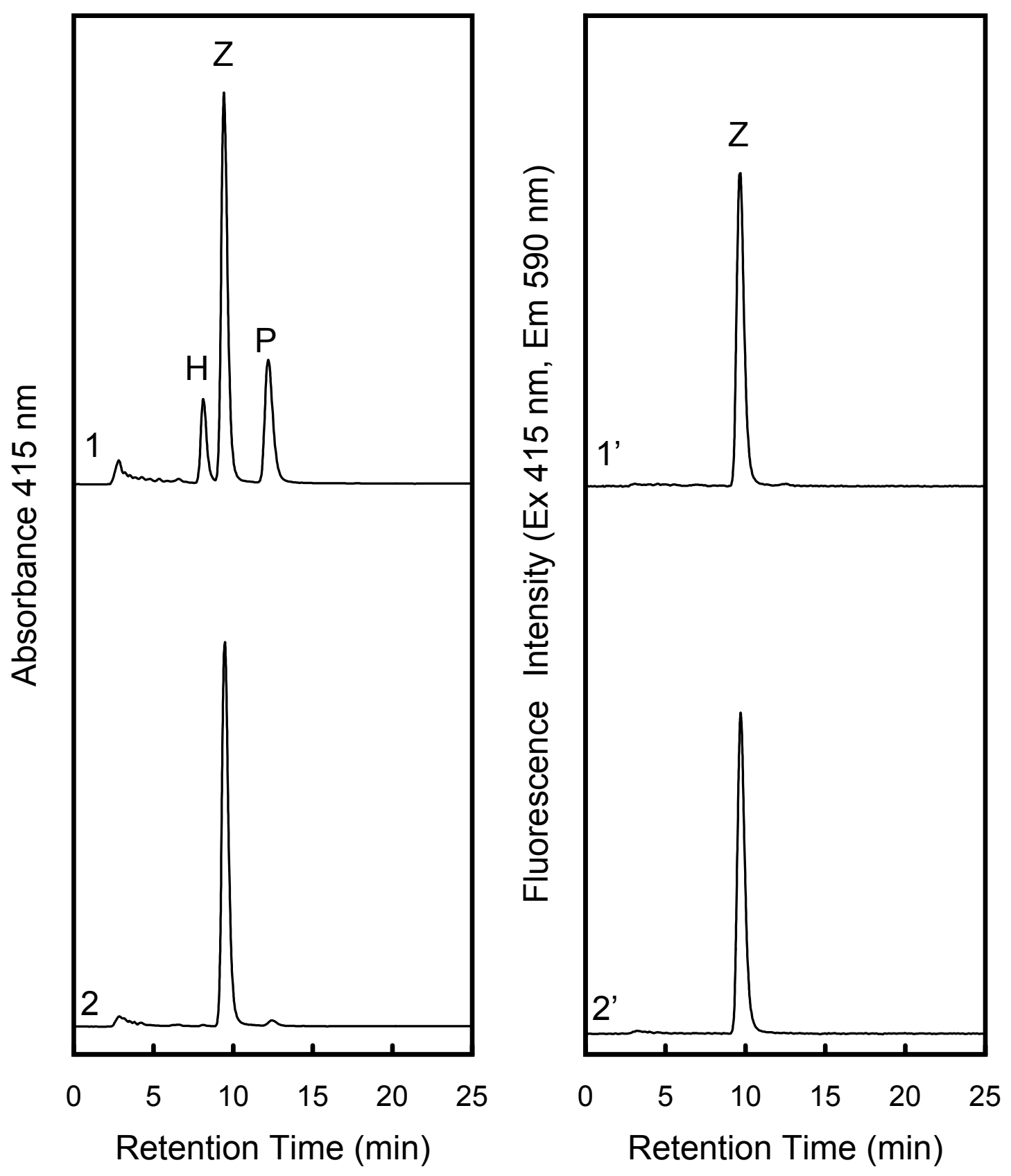

Fig. 4 HPCL elution profile of the red pigment from Parma ham. Traces 1 and 1', Standard solutions. Traces 2 and 2', Parma ham extract. Peaks are as follows; $\mathrm{H}$ : hemin, Z: zinc protoporphyrin IX, P: protoporphyrin IX. 


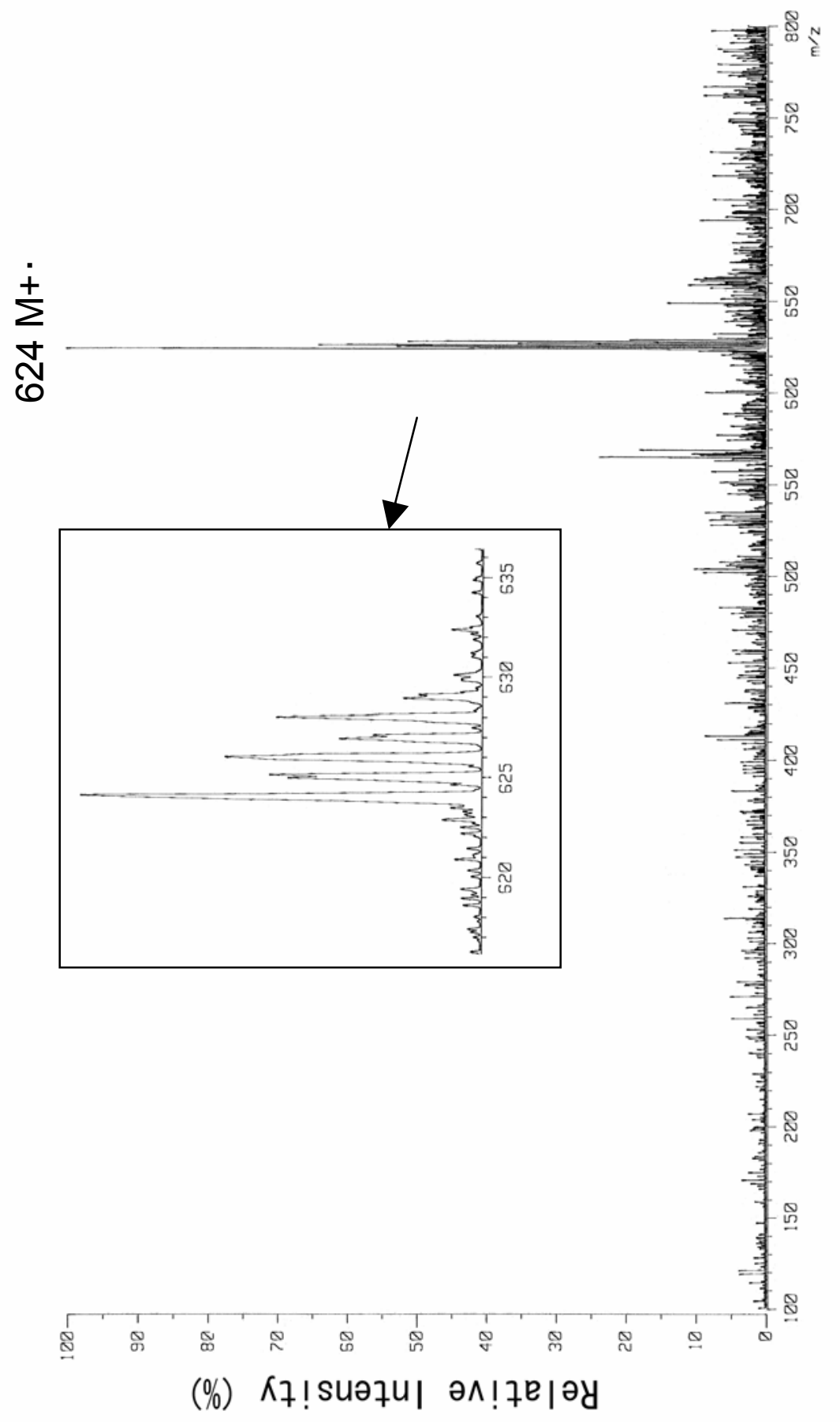

Fig. 5 ESI-HR mass spectra of the red pigment from Parma ham and the magnification (insert). 